223

3

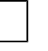
\section{GALPHAO-MEDIATED SIGNALLING IN THE CENTRAL NERVOUS MECHANISMS CONTROLLING SYMPATHETIC OUTFLOW TO THE HEART}

THE ROLE OF INHIBITORY G PROTEIN

R Ang, ${ }^{1}$ L Birnbaumer, ${ }^{2}$ A Gourine, ${ }^{1}$ A Tinker ${ }^{3}{ }^{1}$ UCL; ${ }^{2}$ NIEHS; ${ }^{3}$ OMUL

doi:10.1136/heartjnl-2013-304019.223

Introduction Inhibitory $G$ proteins are known to mediate vagal influences on the heart. However, their role in the central nervous mechanisms of cardiovascular control remain unclear. Previous data have shown mice with global deletion of GalphaO $(\mathrm{G} \alpha \mathrm{O})$ exhibit tachycardia, loss of diurnal variation and fairly selective loss of LF component of HRV with preserved total power suggestive of increased sympathetic tone, likely to be of central origin. We hence hypothesised that in mice, conditional deletion of $\mathrm{GalphaO}(\mathrm{G} \alpha \mathrm{O})$ in the rostral ventrolateral medulla oblongata (RVLM), which contains sympathoexcitatory (pre-sympathetic) neurones, will have a significant impact on autonomic cardiac reflexes.

Methods Using the Cre/LoxP approach, $\mathrm{G} \alpha \mathrm{O}$ was deleted in the RVLM of $\mathrm{G} \alpha \mathrm{O}$ flx/flx mice aged between 8 to 12 weeks (CKO) by stereotaxic delivery of an adenoviral (AdV) vector to trigger expression of Cre and GFP driven by a CMV promoter. Littermates injected with a GFP-only-expressing AdV served as controls. After 1 week, these mice (under urethane anaesthesia, $1.3 \mathrm{~g} / \mathrm{kg}$ IP) were given alternating doses of phenylephrine $(0.5-2 \mathrm{mg} / \mathrm{kg}$, IV) and sodium nitroprusside $(0.1-1 \mathrm{mg} / \mathrm{kg}, \mathrm{IV})$ and the obtained heart rate (HR) and blood pressure (BP) data were used to individually fit sigmoidal baroreflex curves (Figure 1). The animals were then sacrificed and transgene expression was confirmed histologically.

Results Compared to controls, CKO mice ( $\mathrm{n}=4$ in each group) were tachycardic (median minimum HR 608 bpm, IOR 604-639 vs 580 bpm, IOR 576-598) and displayed an increased baroreflex gain

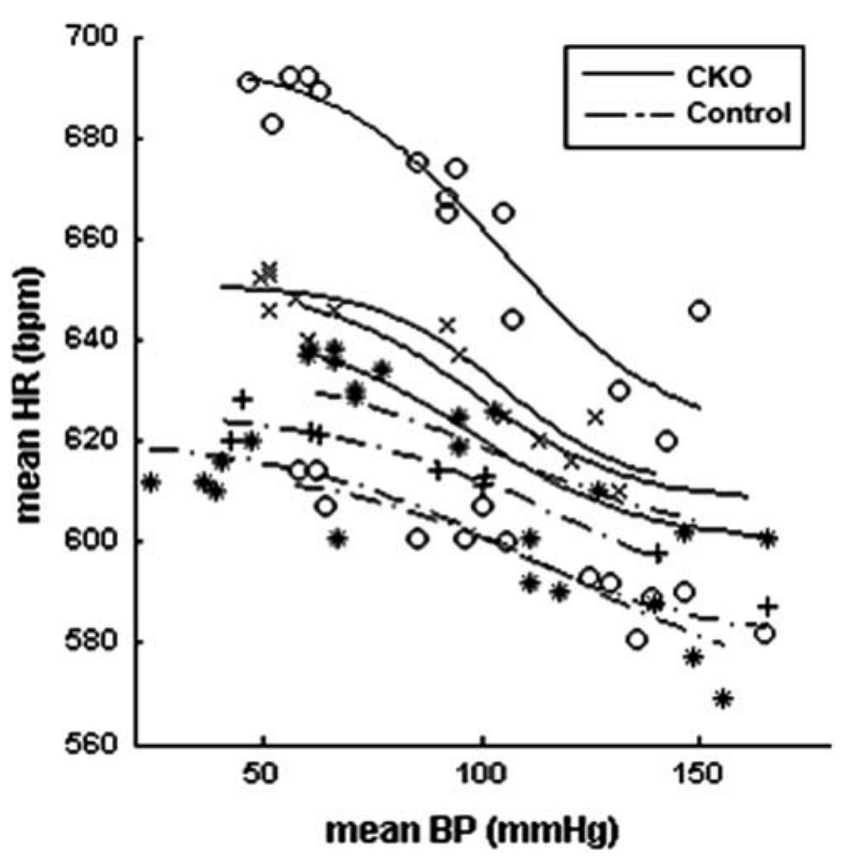

Figure 1

(mean BR gain $0.65 \mathrm{bpm} / \mathrm{mmHg}, 95 \%$ CI $0.46-0.83$ vs $0.35 \mathrm{bpm} /$ mmHg, 95\%CI 0.33-0.37, $\mathrm{p}=0.03$ ).

Conclusion Mice with conditional deletion of $\mathrm{G} \alpha \mathrm{O}$ within the sympathoexcitatory circuits of the brainstem display enhanced baroreflex sensitivity consistent with an increased sympathetic tone. This suggests an important role for $\mathrm{G} \alpha \mathrm{O}$-mediated signalling in the central nervous inhibitory mechanisms controlling sympathetic outflow. 